\title{
High Frequency PWM-Controlled Current-Mode Resonant DC-DC Converter with Boost Conversion
}

\author{
Akinori Hariya*, Ken Matsuura**, Hiroshige Yanagi**, Satoshi Tomioka**, \\ Yoichi Ishizuka*, and Tamotsu Ninomiya* \\ Nagasaki University*, TDK-Lambda Corporation** \\ 1-14 Bunkyo-machi, Nagasaki-shi*, 2704-1 Settaya-machi, Nagaoka-shi** \\ Nagasaki, Japan*, Niigata, Japan** \\ Tel.: $+81 /(95)-819-2556$ \\ Fax: $+81 /(95)-819-2556$ \\ E-Mail: bb52312202@cc.nagasaki-u.ac.jp
}

\section{Acknowledgements}

The authors would like to thank Mr. Shohei Iwasaki of Nagasaki University Technical staff, for him technical support.

\section{Keywords}

Gallium Nitride (GaN), High frequency power converter, Pulse Width Modulation (PWM), Resonant converter.

\begin{abstract}
In this paper, a new pulse width modulation (PWM) control method for the isolated current-mode resonant converter with a fixed switching frequency is presented. The circuit topology is the same as a conventional resonant converter with synchronous rectification and without any additional components. The control technique for the output voltage regulation is proposed with the unique PWM control for synchronously-rectifying switches. By using the transformer's leakage inductance and the PWM control, the boost conversion can be realized. Also, the zero-voltage switching (ZVS) operation can be done for primary switches, simultaneously. Some experiments have been done with $5 \mathrm{MHz}$ isolated DC-DC converter which has Gallium Nitride field effect transistor (GaN-FET).
\end{abstract}

\section{Introduction}

Recently, high-efficiency and high power-density DC-DC converters have been required in a wide field of applications. Corresponding to this requirement, the current-mode resonant DC-DC converters featuring high efficiency have been continuously developed. Furthermore, the increase in the switching frequency of these converters is considered to be one of key technologies needed for downsizing. We have also developed a $5 \mathrm{MHz}$ current-mode resonant DC-DC converter, and presented its prominent features previously [1]. The converter had an input/output voltage of $48 \mathrm{~V} / 12 \mathrm{~V}$ and a power rating of $120 \mathrm{~W}$. In this converter, GaN-FETs were utilized as semiconductor switches, which were suitable for high-frequency switching operation. Also, another researches have been proved utilizing GaN-FET for high frequency converter is very practical [2-5]. Current-mode resonant DC-DC converters are usually controlled by pulse frequency modulation (PFM). However, in case of wide regulation range, the variation of switching frequency will also be wide. By the variation of switching frequency, the noise frequency of the converter is changed. As a result, the noise filter of the converter which can clear the noise in wide range leads to high cost. Another problem is the variation of the circuit parameters with the dependence of switching frequency.

To solve the problems, this paper presents a new PWM control method for the current-mode resonant converter with a fixed switching frequency. This converter topology is the same as the conventional current-mode resonant converter with synchronous rectification and without any additional 
components. By using transformer's leakage inductance and synchronously rectifying switches, the new control method for boost conversion is performed. This proposed converter maintains some fundamental characteristics of resonant operation such as ZVS of main switches.

In the previous literatures, some PWM-controlled current-mode resonant DC-DC converters have been presented [6-10]. The most recent PWM-controlled resonant converters utilized the control technique for duty ratio of primary-side switches, and some additional components such as an active clamp switch were needed. However, for the output-voltage regulation in this proposed converter, only the duty ratio of synchronously rectifying switches in the secondary side is controlled, and additional components are not necessary.

In this paper, the novel PWM control method for the current-mode resonant converter with a fixed switching frequency is proposed. In the next section, general resonant converter is described. After the section, the ability of the novel voltage regulation technique are revealed which is with boost circuit composed of the transformer's leakage inductance and the synchronous rectifier switches, and diode in the secondary side. In the final section, some experimental results have confirmed the capability of output-voltage control for the $5 \mathrm{MHz}$ resonant converter with GaN-FET.

\section{The operation for current-mode resonant converter in $\mathrm{MHz}$ order}

Recently, for DC-DC converters, high power-density and high power-efficiency are strongly demanded. To realize the high power-density, operating DC-DC converter in the high frequency is valid because of the minimizing the value of the magnetic transformer. But, with the high frequency switching, switching loss is becoming larger. To suppress the switching loss, the current-mode resonant DC-DC converter is widely used. Generally, the current-mode resonant DC-DC converter is controlled by PFM control which varies switching frequency [11]. As shown in Fig. 1, the red dotted line shows the operating line which depends on the switching frequency. It can be seen that the output voltage can be controlled with PFM.

In $\mathrm{MHz}$ order operation with PFM control, these problems are occurred:

1) The MHz-order filter for the wide-band is needed.

2) The components parameters are varied easily by frequency. Though, the design of PFM control for the MHz-order operation would be harder.

From the reasons, it seems that the MHz order operation with PFM control cannot be appropriate. Therefore, in this paper, the MHz order operation with PWM control for the current-mode resonant DC-DC converter is proposed.

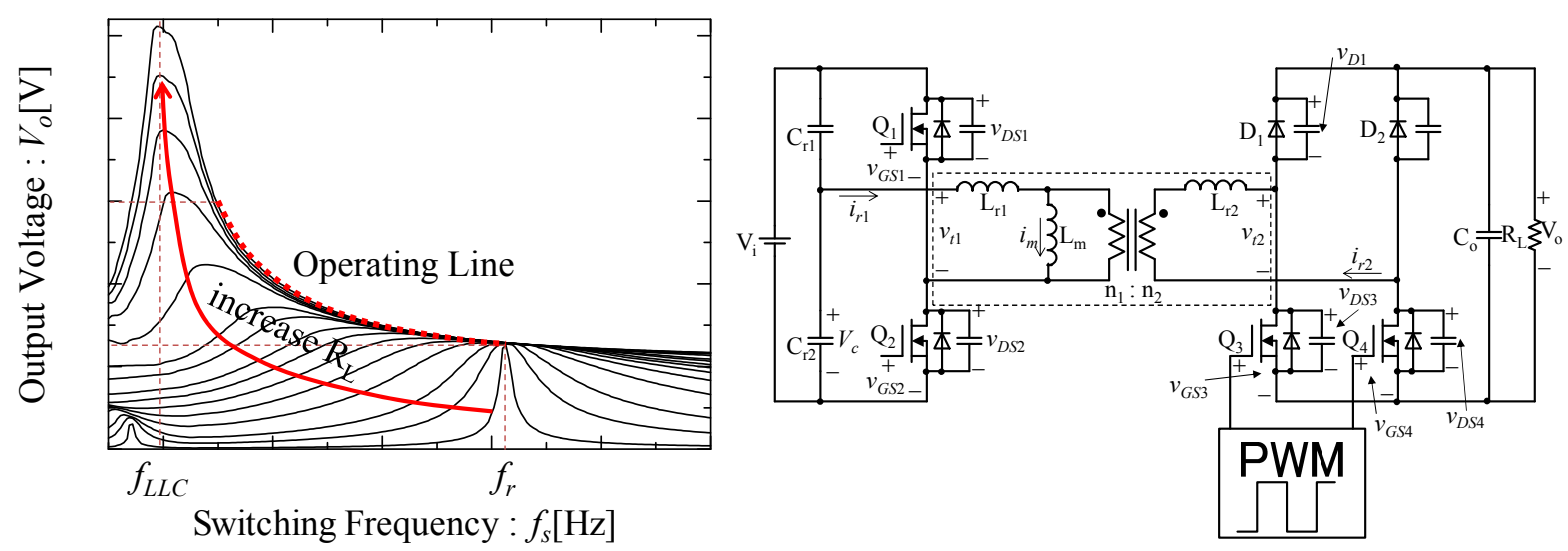

Fig. 1: Control characteristics

Fig. 2: Circuit diagram 


\section{The proposed PWM-controlled current-mode resonant converter}

\section{Basic topology and operations}

The circuit topology is based on a half-bridge type current-mode resonant converter as shown in Fig. 2 . The primary-side is the half-bridge topology. $\mathrm{Q}_{1}$ and $\mathrm{Q}_{2}$ are driven in $50 \%$ duty ratio, alternatively. $\mathrm{C}_{\mathrm{r} 1}$ and $\mathrm{C}_{\mathrm{r} 2}$ are the resonant capacitors which have same capacitances and also make averaged voltage of $\mathrm{V}_{\mathrm{c}}$ to a half of the input. The inside of the broken line is the magnetic transformer which equivalently indicated that $\mathrm{L}_{\mathrm{r} 1}$ and $\mathrm{L}_{\mathrm{r} 2}$ are leakage inductor, and $\mathrm{L}_{\mathrm{m}}$ is the transformer's magnetizing inductance. The turn ratio is $\mathrm{n}_{1}: \mathrm{n}_{2} . \mathrm{L}_{\mathrm{r} 1}$ and $\mathrm{L}_{\mathrm{r} 2}$ are used as the resonant inductor.

The secondary-side is the full-bridge topology composed with diodes $\mathrm{D}_{1}$ and $\mathrm{D}_{2}$ for high-side arm switches, and transistors $\mathrm{Q}_{3}$ and $\mathrm{Q}_{4}$ for low-side arm switches. The $\mathrm{Q}_{3}$ and $\mathrm{Q}_{4}$ are controlled with PWM. Each on-term of $\mathrm{Q}_{3}$ and $\mathrm{Q}_{4}$ is allowed to be mutually overlapped. To make analysis this converter, all of the transistors are assumed to have parasitic output capacitance and body diode, respectively.

\section{Principle of the proposed PWM control method}

In Fig. 3, the waveforms are shown. The duty ratio of $\mathrm{Q}_{3}$ and $\mathrm{Q}_{4}$ is defined as follows: $D=T_{o n} / T_{s}$, where $T_{s}$ is the switching period, and $T_{o n}$ is the on-term. The minimum duty ratio is set to be 0.5 , whose operation is equivalent to the conventional synchronous rectifier. When the duty ratio is larger than 0.5 , the converter is operated in the boost-mode operation. Figure 3 shows waveforms in the boost-mode operation, where the duty ratio $D$ is chosen to be larger than 0.5 . During state 1 and state $3, Q_{3}$ and $Q_{4}$ are overlapped as indicated with the gray area.

The relations for the switch condition and the circuit operation states are summarized in Table I. The equivalent circuits for each state of a half switching term are shown in Fig. 4. In this figure, the switches drawn with weak colors represent OFF, and red arrowed line represents current flow. The description for each state is described below.

State 1: All of the primary side switches are turned OFF by the controller, which is called dead-time. The parasitic capacitor of $\mathrm{Q}_{1}$ is discharged by a half of resonant inductance current $i_{r l}$.

State 2: Regardless of the discharge is completed, the current flows sustainably. Therefore, the direction of the voltage applied to drain-source of $\mathrm{Q}_{1}$ is inverted, and the body diode of $\mathrm{Q}_{1}$ becomes $\mathrm{ON}$.

State 3: The switch $\mathrm{Q}_{1}$ is turned $\mathrm{ON}$, and the body diode of $\mathrm{Q}_{1}$ becomes OFF. The same state of primary side is continued between state 3 and state 6 . On the secondary side, the leakage inductance $\mathrm{L}_{\mathrm{r} 2}$ is magnetized by $i_{r 2}$.

State 4: After $\mathrm{Q}_{4}$ is turned OFF, the direction of the voltage applied to $\mathrm{D}_{2}$ is inverted, and diode of $\mathrm{D}_{2}$ becomes $\mathrm{ON}$. The inductance current which is magnetized in state 3 flows through diode $\mathrm{D}_{2}$ and switch $\mathrm{Q}_{3}$, to the load.

State 5: After the $\mathrm{V}_{\mathrm{o}}$ becomes larger than $\mathrm{V}_{\mathrm{DS} 4}$, the $\mathrm{D}_{2}$ becomes OFF. The parasitic capacitance of $\mathrm{Q}_{4}$ is discharged.

State 6: Regardless of the discharge is completed, the current flows sustainably. Therefore, the direction of the voltage applied to drain-source of $\mathrm{Q}_{4}$ is inverted, and the body diode of $\mathrm{Q}_{4}$ becomes $\mathrm{ON}$.

After state 6, the switch $\mathrm{Q}_{4}$ is turned ON, and the body diode of $\mathrm{Q}_{4}$ becomes OFF. From the state 3 to 5 , the output voltage is increased by the inductance charging current. The inductance current depends on the duty ratio $D$. This reveals the boost mode operation. Also, from the state 1 to 3 , ZVS operation for $\mathrm{Q}_{1}$ can be confirmed. And, from the state 5 to 6 , ZVS operation for $\mathrm{Q}_{4}$ can be confirmed. 
Table I: The relations for the switch condition and the circuit operation states

\begin{tabular}{|c|c|c|c|c|c|c|}
\hline & State 1 & State 2 & State 3 & State 4 & State 5 & State 6 \\
\hline $\mathrm{Q}_{1}$ & OFF & OFF & ON & ON & ON & ON \\
\hline $\mathrm{Q}_{2}$ & OFF & OFF & OFF & OFF & OFF & OFF \\
\hline The body diode of $\mathrm{Q}_{1}$ & OFF & ON & OFF & OFF & OFF & OFF \\
\hline The body diode of $\mathrm{Q}_{2}$ & OFF & OFF & OFF & OFF & OFF & OFF \\
\hline $\mathrm{Q}_{3}$ & ON & ON & ON & ON & ON & ON \\
\hline $\mathrm{Q}_{4}$ & ON & ON & ON & OFF & OFF & OFF \\
\hline The body diode of $\mathrm{Q}_{3}$ & OFF & OFF & OFF & OFF & OFF & OFF \\
\hline The body diode of $\mathrm{Q}_{4}$ & OFF & OFF & OFF & OFF & OFF & ON \\
\hline $\mathrm{D}_{1}$ & OFF & OFF & OFF & OFF & OFF & OFF \\
\hline $\mathrm{D}_{2}$ & OFF & OFF & OFF & ON & OFF & OFF \\
\hline
\end{tabular}

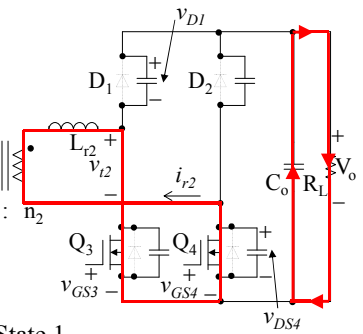

(a) State 1

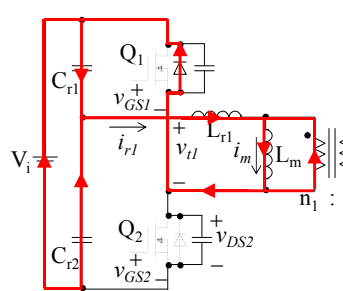

(b) State 2
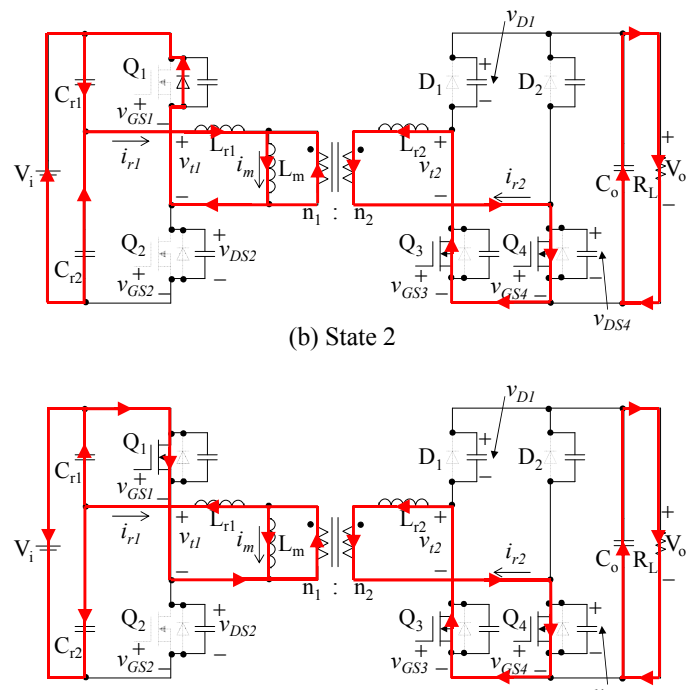

(c) State 3

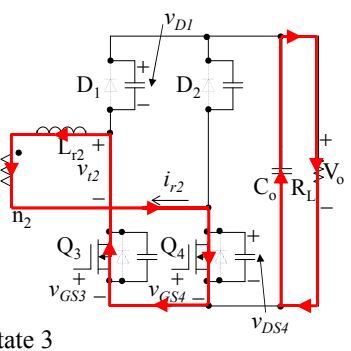

Fig. 4: The equivalent circuits for each state

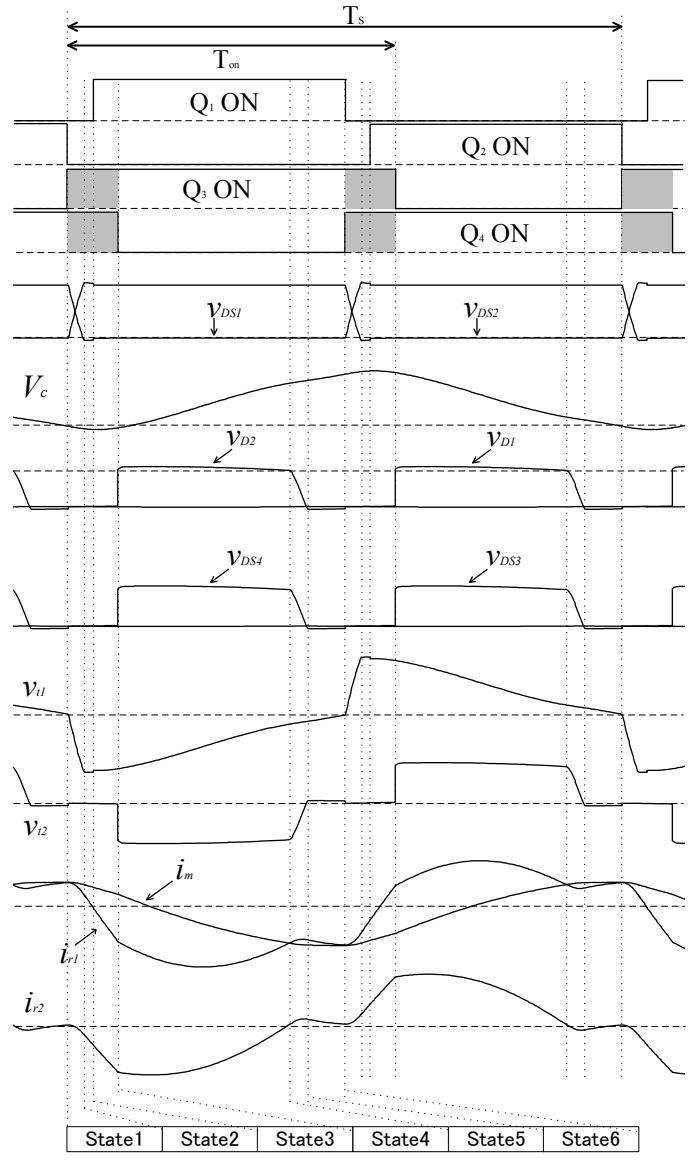

Fig. 3: Waveforms
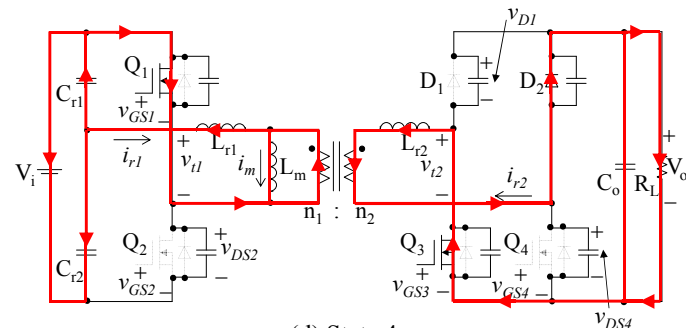

(d) State 4

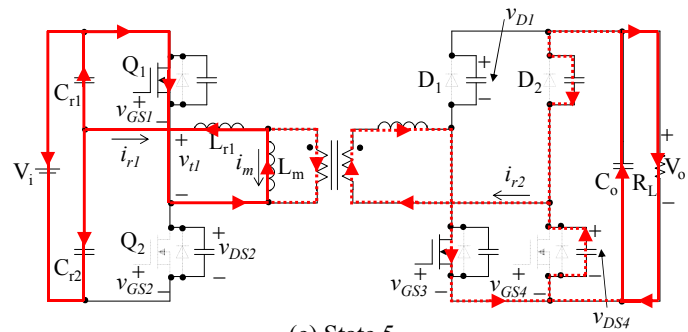

(e) State 5

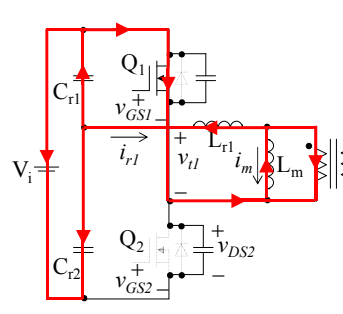

(f) State 6

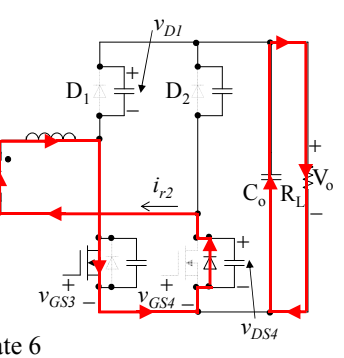




\section{Experimental results}

The prototype system for the experiments is shown in Fig. 5. As a prototype digital controller, field programmable gate array (FPGA) Cyclone IV is used, which generates individual gate signal for each switches. The on-term of the gate signals are manually changed with software. In the future, the digital controller will be packed in one-chip. The resolution of the gate signals is $1 \mathrm{~ns}$.

Some experiments have been carried out with parameters as shown in Table II, and $12 \mathrm{~V}$ of constant output voltage with open loop control. Components used in the experiment are shown in Table III. As the primary side GaN-FETs, EPC2001 whose voltage rating is $100 \mathrm{~V}$, is used. As the secondary side GaN-FETs, EPC2015 whose voltage rating is 40V, is used. LM5113 is used as a gate driver for halfbridge-connected GaN-FETs. Single driver component is used in the primary side and two drivers are used in the secondary side.

The main circuit of the proposed 5MHz DC-DC converter is shown in Fig. 6 (a) and (b). The total volume of the main circuit of the proposed $5 \mathrm{MHz}$ DC-DC converter is $16.14 \mathrm{~cm}^{3}$, where depth and width are $3.00 \mathrm{~cm}$ and $6.81 \mathrm{~cm}$, and highest point is $0.79 \mathrm{~cm}$. The reason of the selected switches and magnetic transformer materials are described in [1].

Firstly, with these experimental conditions, static evaluations for current-mode resonant DC-DC converter with PWM control are shown. In the next, the method of maintaining the ZVS condition against load current and input voltage variation is described.

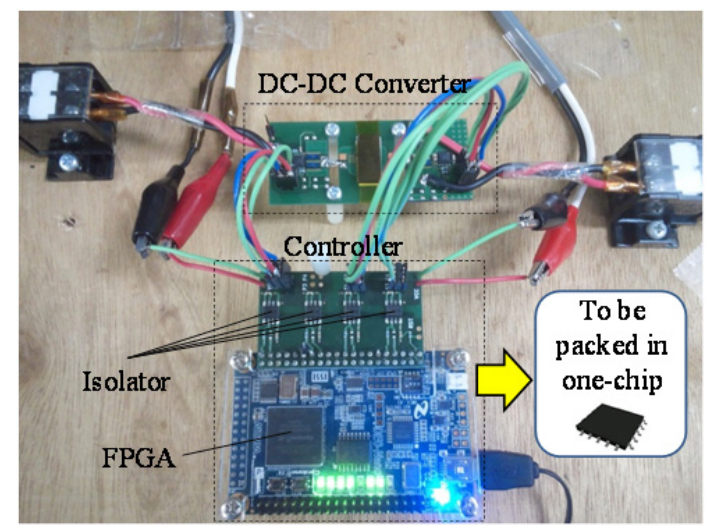

Fig. 5: Prototype system for the experiments.

Table II: Experimental parameters

\begin{tabular}{|c|c|}
\hline Input voltage: $\mathrm{V}_{\mathrm{i}}$ & $36 \mathrm{~V} \sim 44 \mathrm{~V}$ \\
\hline Output reference voltage: $\mathrm{V}_{\mathrm{o} \text { (ref) }}$ & $12 \mathrm{~V}$ \\
\hline Maximum power rating: $\mathrm{P}_{\mathrm{o}}$ & $96 \mathrm{~W}$ \\
\hline Transformer ratio $\mathrm{n}_{1}: \mathrm{n}_{2}$ & $2: 1$ \\
\hline Switching frequency: $\mathrm{f}_{\mathrm{s}}$ & $5 \mathrm{MHz}$ \\
\hline Resonant frequency: $\mathrm{f}_{\mathrm{r}}$ & $4.98 \mathrm{MHz}$ \\
\hline $\begin{array}{c}\text { Transformer leakage inductance: } \\
\mathrm{L}_{\mathrm{r}}\end{array}$ & $33 \mathrm{nH}$ \\
\hline $\begin{array}{c}\text { Transformer magnetizing } \\
\text { inductance: } \mathrm{L}_{\mathrm{m}}\end{array}$ & $200 \mathrm{nH}$ \\
\hline Resonant capacitor: $\mathrm{C}_{\mathrm{r} 1}, \mathrm{C}_{\mathrm{r} 2}$ & $15.5 \mathrm{nF}$ \\
\hline Input capacitor: $\mathrm{C}_{\mathrm{i}}$ & $2 \mu \mathrm{F}$ \\
\hline Output capacitor: $\mathrm{C}_{\mathrm{o}}$ & $18.8 \mu \mathrm{F}$ \\
\hline
\end{tabular}

Table III: Experimental components

\begin{tabular}{|c|c|c|}
\hline & $\begin{array}{c}\text { Manufact } \\
\text { ure }\end{array}$ & $\begin{array}{c}\text { Part Name/ } \\
\text { Material }\end{array}$ \\
\hline $\begin{array}{c}\text { Primary side } \\
\text { GaN-FET }\end{array}$ & EPC & EPC2001 \\
\hline $\begin{array}{c}\text { Secondary side } \\
\text { GaN-FET }\end{array}$ & EPC & EPC2015 \\
\hline FET Driver & $\begin{array}{l}\text { TEXAS } \\
\text { INSTRU } \\
\text { MENTS }\end{array}$ & LM5113 \\
\hline Diode & DIODES & PDS1040L \\
\hline $\begin{array}{c}\text { Transformer } \\
\text { Core Material }\end{array}$ & TDK & $\begin{array}{c}\text { NiZn Ferrite } \\
\text { Core }\end{array}$ \\
\hline $\begin{array}{l}\text { Resonant } \\
\text { Capacitor }\end{array}$ & TDK & $\begin{array}{c}\mathrm{C} 1608 \mathrm{C} 0 \mathrm{G} 1 \mathrm{H} 3 \\
92 \mathrm{~J}\end{array}$ \\
\hline $\begin{array}{c}\text { Input } \\
\text { Capacitor }\end{array}$ & TDK & $\begin{array}{c}\text { C3216X7R1H1 } \\
\text { 05K }\end{array}$ \\
\hline $\begin{array}{c}\text { Output } \\
\text { Capacitor }\end{array}$ & TDK & $\begin{array}{c}\text { C2012X7R1E4 } \\
75 \mathrm{M} \\
\end{array}$ \\
\hline FPGA & TDK & $\begin{array}{c}\text { DE0-nano } \\
\text { (Cyclone IV) }\end{array}$ \\
\hline Isolator & $\begin{array}{l}\text { TEXAS } \\
\text { INSTRU } \\
\text { MENTS }\end{array}$ & ISO722 \\
\hline
\end{tabular}




\section{Static evaluations for current-mode resonant DC-DC converter with PWM control}

The static characteristics of the 5MHz PWM-controlled DC-DC converter are exhibited. In Fig. 7, the experiment results for the static characteristics of duty ratio $D$ of secondary switches with manually regulated output voltage $V_{o}=12 \mathrm{~V}$. The experiments have been done under $100^{\circ} \mathrm{C}$ of board temperature condition. It can be seen that the output voltage can be regulated with $D$ against the variation of load current or input voltage. From the results, PWM control can be accomplished for this circuit.

\section{The method of maintaining the ZVS condition against load current and input voltage variation}

The maintaining ZVS condition against load current and input voltage variation is one of the design targets for the resonant converter, even in the PWM control. As mentioned above, before the switch is turned ON, the parasitic capacitor of switch is discharged by resonant inductance current. However, at the conditions of the heavy load or the below of the regulated input voltage, drain-source voltage of each switches cannot achieve the ZVS operation, if this circuit operated with fixed on-term of primary side switches. The reason for occurring non-ZVS is not flowing enough amount of drain current, corresponding to the resonant current, at $t_{0}$ as shown in Fig. 8 (a). As a comparison, the ZVS achieved result shown in Fig. 8 (b). As an example, the simulation results for the relation of $i_{D I}\left(t_{0}\right)$ and input voltage or load current is shown in Fig. 9 (a) and (b). Same result is applied for $i_{D 2}\left(t_{2}\right)$. From the results, the drain current is decreased with the increasing of load current or the decreasing of input voltage. To compensate the amount of drain current for achieving the ZVS condition, the phase-shift

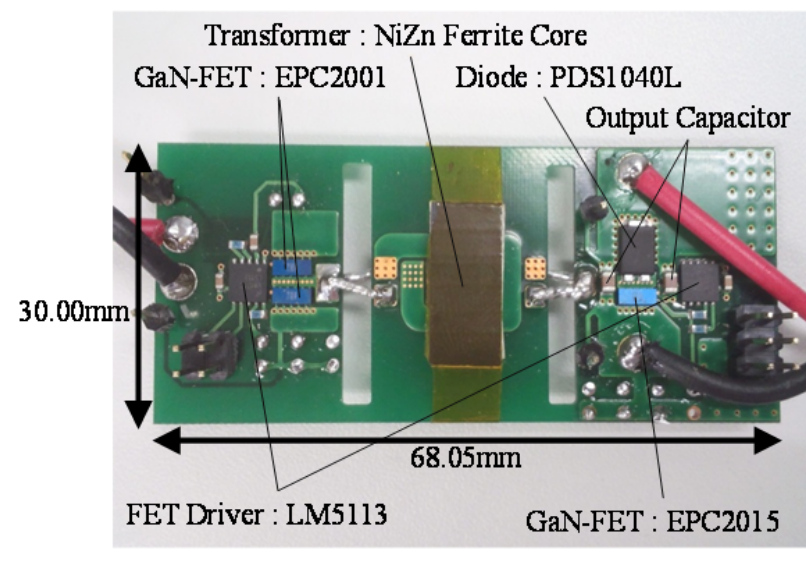

(a) The upper side of the converter

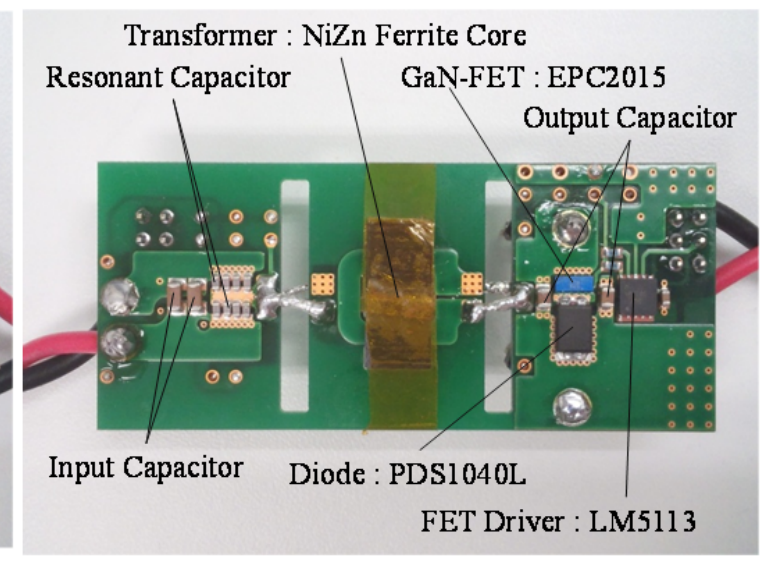

(b) The lower side of the converter

Fig. 6: The main circuit of the proposed 5MHz DC-DC converter

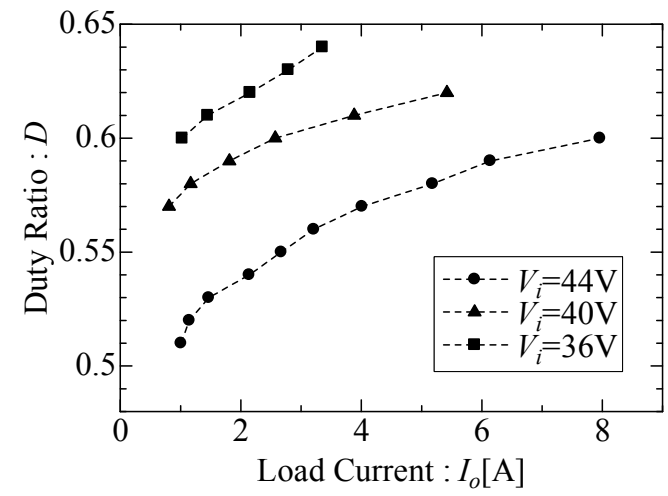

(a)

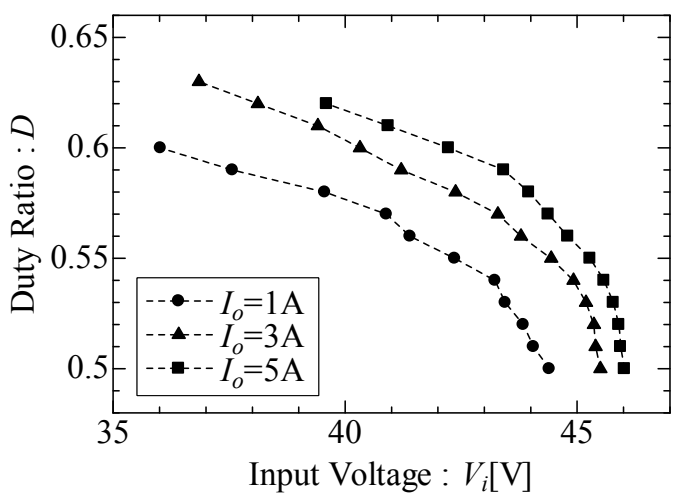

(b)

Fig. 7: The static characteristics of duty ratio $D$ of secondary switches with manually regulated output voltage $V_{o}=12 \mathrm{~V}$ 
between primary and secondary switches are valid. The effect of phase shift for ZVS is shown in Fig. 10 with experimental results. From the results, applying the phase-shift $\Delta t_{p s}$ can be seen achieving ZVS. The reason for the results is that the phase-shift controls the amount of magnetizing inductance current. That means the resonant current can be controlled by the phase-shift.

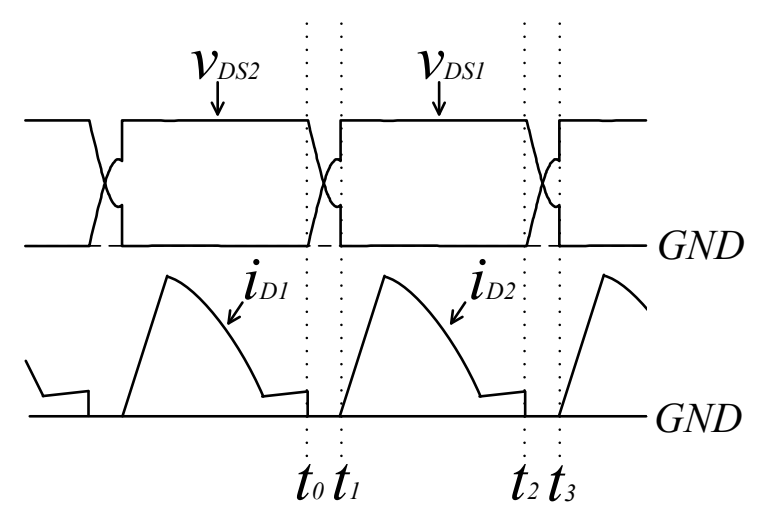

(a) non-ZVS condition

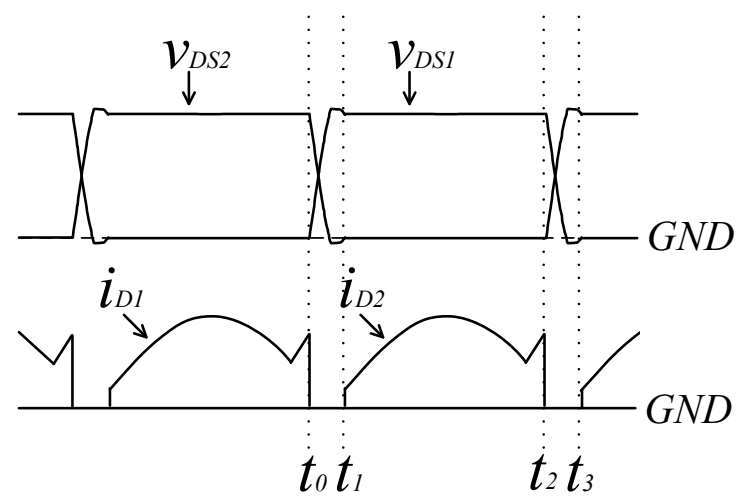

(b) ZVS condition

Fig. 8: The relations of ZVS conditions and drain current

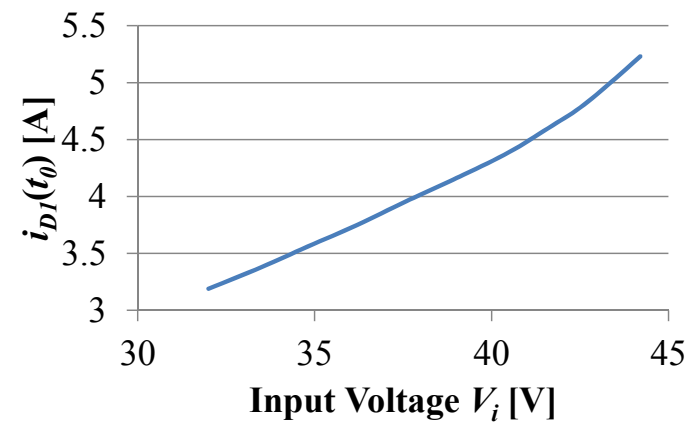

(a) Input voltage

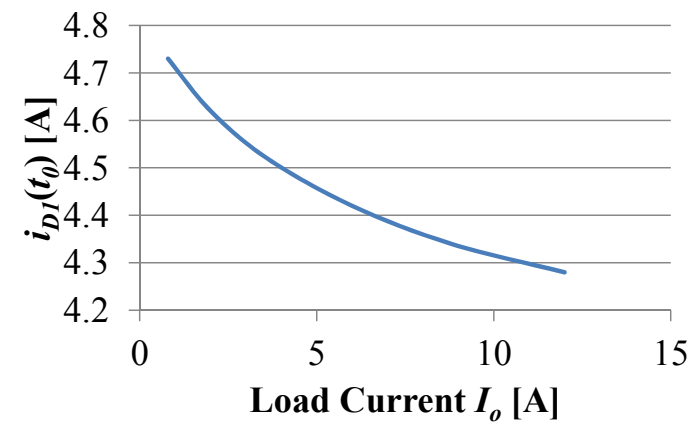

(b) Load current

Fig. 9: The simulation results for the relation of drain current $i_{D I}\left(t_{0}\right)$ and input voltage or load current

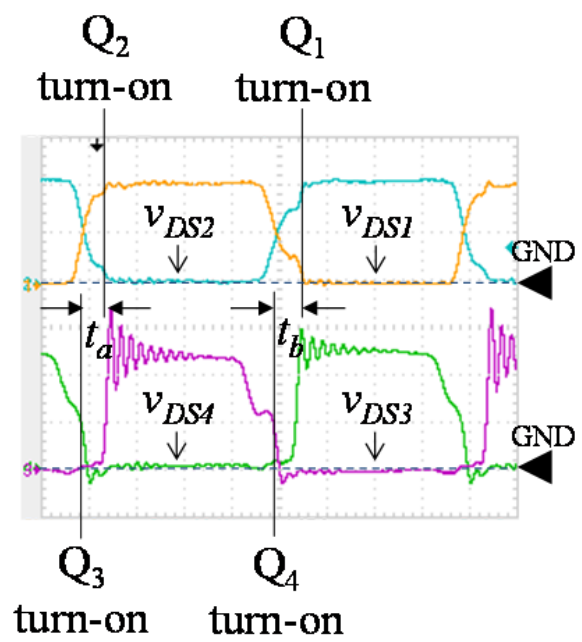

(a) Not applying phase-shift

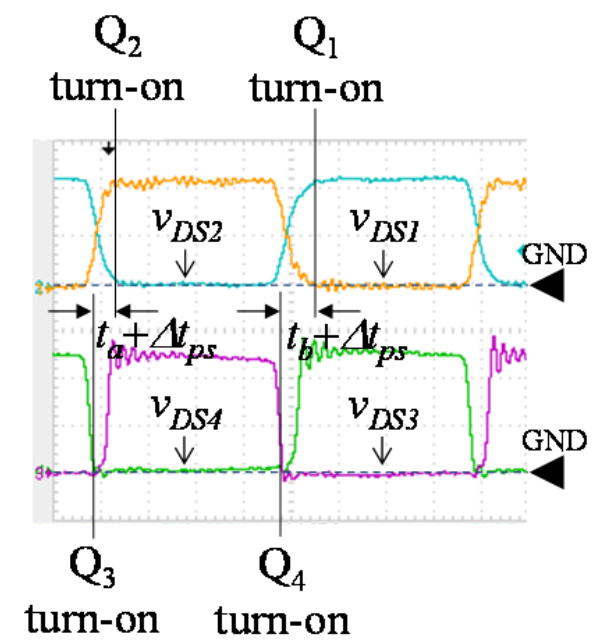

(b) Applying phase-shift

Fig. 10: Waveforms at $D=0.55, I_{o}=5 \mathrm{~A}, V_{o}=12 \mathrm{~V}$

( $v_{D S 1}: 20 \mathrm{~V} / \mathrm{div}, v_{D S 2}: 20 \mathrm{~V} / \mathrm{div}, v_{D S 3}: 5 \mathrm{~V} / \mathrm{div}, v_{D S 4}: 5 \mathrm{~V} / \mathrm{div}$, Horizon: $\left.25 \mathrm{~ns} / \mathrm{div}\right)$ 
Figure 11 and 12 shows the experiment with the phase-shift. Figure 11 shows the ZVS operation can be achieved even when the input voltage has $10 \%$ variation. Figure 12 shows the ZVS operation can be achieved even when the load current has $20 \%$ variation. The duty ratio of secondary side is regulated to be constant $12 \mathrm{~V}$ of output voltage in both $10 \%$ of input voltage variation and $20 \%$ of load current variation. The current $i_{r l}$ is calculated from the differential value of $v_{c}$ because of the difficulty of the current measurement in the high frequency operation. The red dotted line shows achieving ZVS operation and enough resonant current. From the results, the current remains at $t_{0}$ which is the turn OFF time of $\mathrm{Q}_{1}$. This current discharges the parasitic capacitor of $\mathrm{Q}_{2}$ during dead-time from $t_{0}$ to $t_{1}$. Thus, $\mathrm{Q}_{2}$ is turned on with zero voltage at $t_{l}$. And it is revealed that the enough large resonant current is effective to achieve the ZVS operation, and the current can be controlled with the phase-shift.

Figure 13 shows the primary voltage of transformer. With the phase-shift operation, also the decreasing of the even-number-order harmonic from the primary voltage of the transformer can be achieved. It can be seen that the compensation technique can be valid for not only ZVS operation but effective energy transmission.

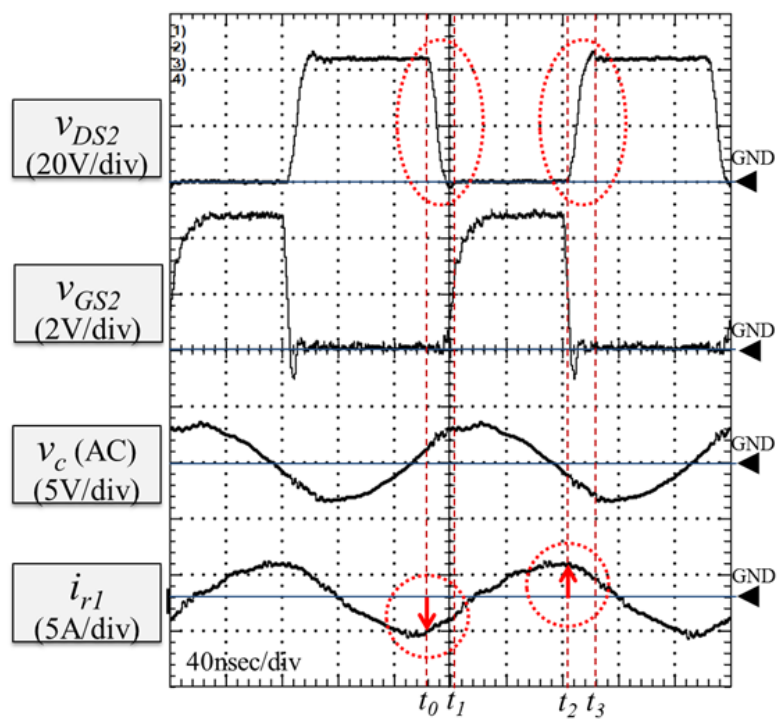

(a) $V_{i}=44 \mathrm{~V}, D=0.55, \Delta t_{p s}=7 \mathrm{nsec}$

Fig. 11: Waveforms at $I_{o}=3 \mathrm{~A}, V_{o}=12 \mathrm{~V}$

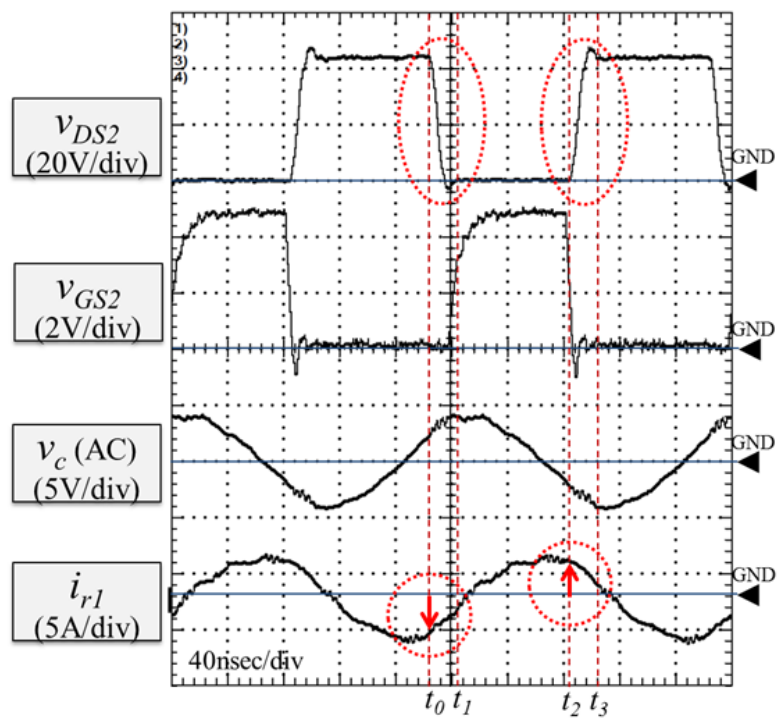

(a) $I_{o}=4 \mathrm{~A}, D=0.57, \Delta t_{p s}=11 \mathrm{nsec}$

Fig. 12: Waveforms at $V_{i}=44 \mathrm{~V}, V_{o}=12 \mathrm{~V}$

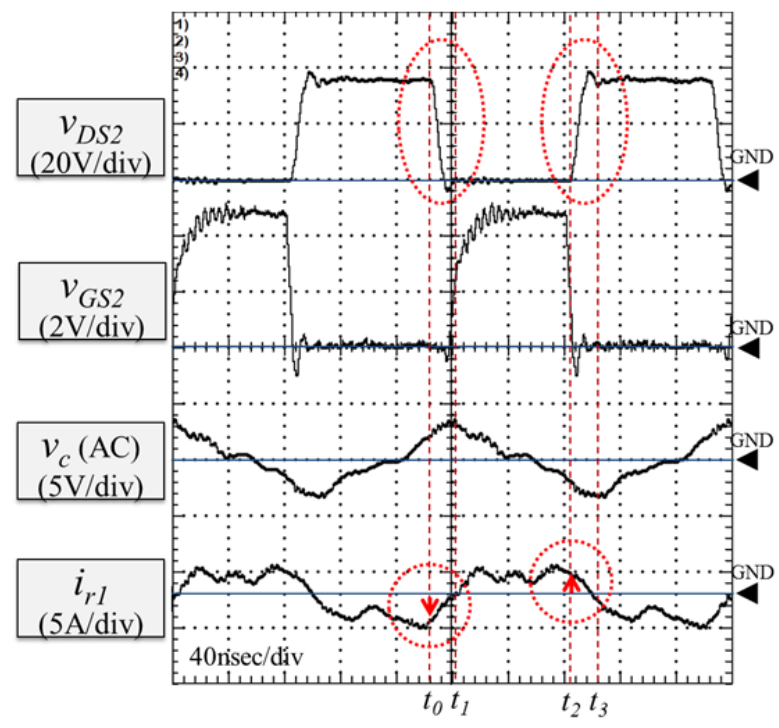

(b) $V_{i}=36 \mathrm{~V}, D=0.63, \Delta t_{p s}=14 \mathrm{nsec}$

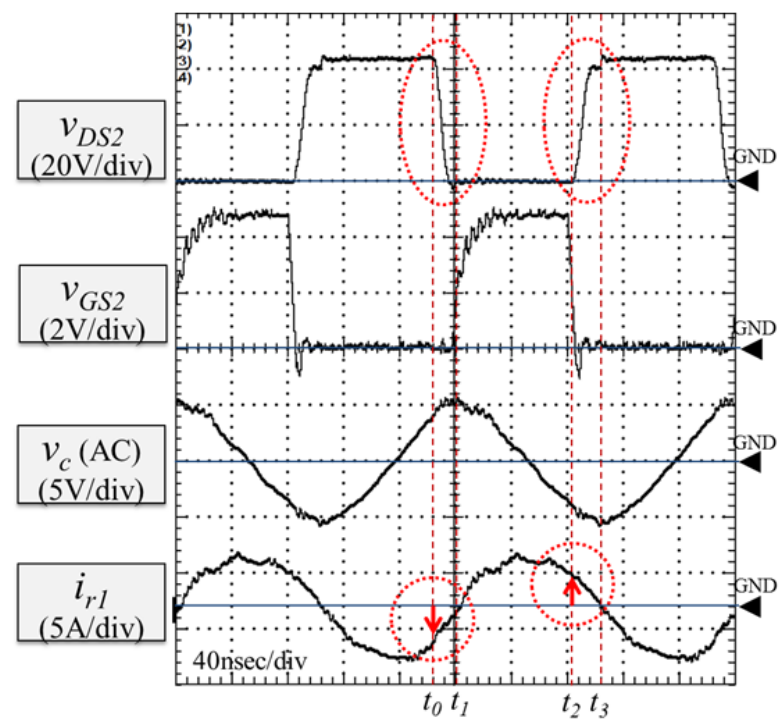

(b) $I_{o}=6 \mathrm{~A}, D=0.59, \Delta t_{p s}=12 \mathrm{nsec}$ 
It is hard to measure the distribution of the power loss of this circuit because of the high power-density. Instead of power measurement, thermographic image as shown in Fig. 14, has been taken of the breadboard at point A in Fig. 15. From the results, the surface temperature of components such as GaN-FET $\mathrm{Q}_{1}$, primary FET driver and the transformer can be suppressed with the phase-shift. However, the temperature of the secondary side is still in high level even with the phase-shift. It is mentioned that the large secondary current and large duty ratio affects the loss of secondary side which is conduction loss of secondary side diodes and FET.

The power efficiency of the converter is shown in Fig. 15. The maximum power efficiency is $89.4 \%$. From the Fig. 14 and Fig. 15, the power loss of primary side is improved by the phase-shift. However, the total power efficiency improvement cannot be found the effect of the phase-shift because of the large power loss of the secondary side.

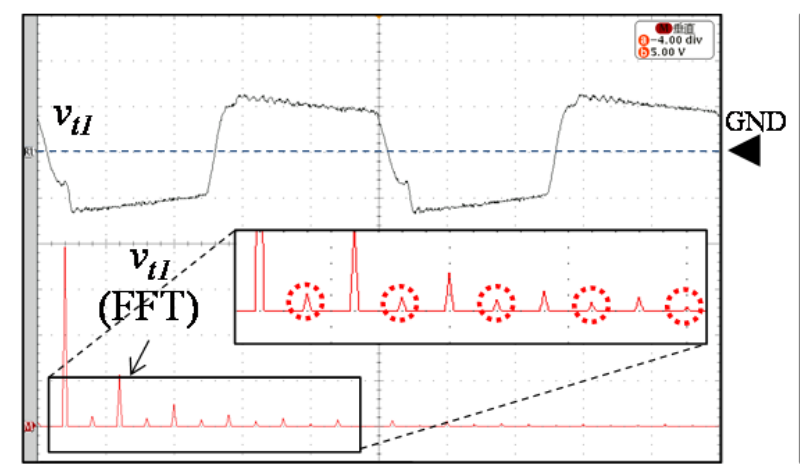

(a) Non- applying phase-shift

Fig. 13: Waveform at $D=0.55, I_{o}=5 \mathrm{~A}, V_{o}=12 \mathrm{~V}$

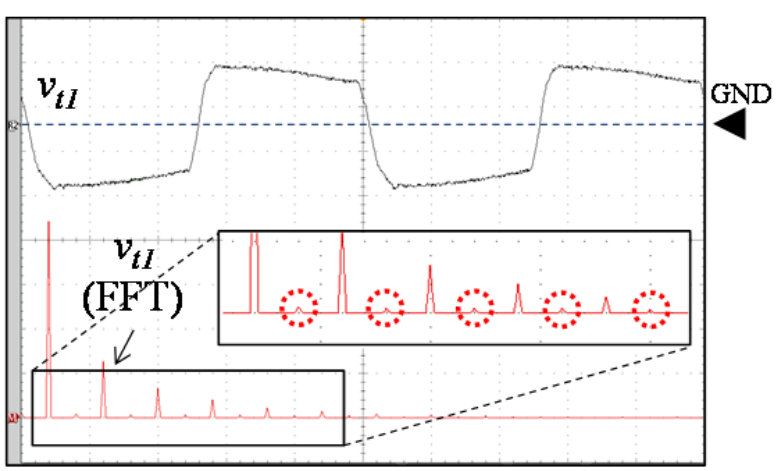

(b) Applying phase-shift

( $v_{t l}: 20 \mathrm{~V} / \mathrm{div}$, Horizon: 40ns/div; $v_{t l}(\mathrm{FFT}): 5 \mathrm{~V} / \mathrm{div}$, Horizon: $12.5 \mathrm{MHz} / \mathrm{div}$ )

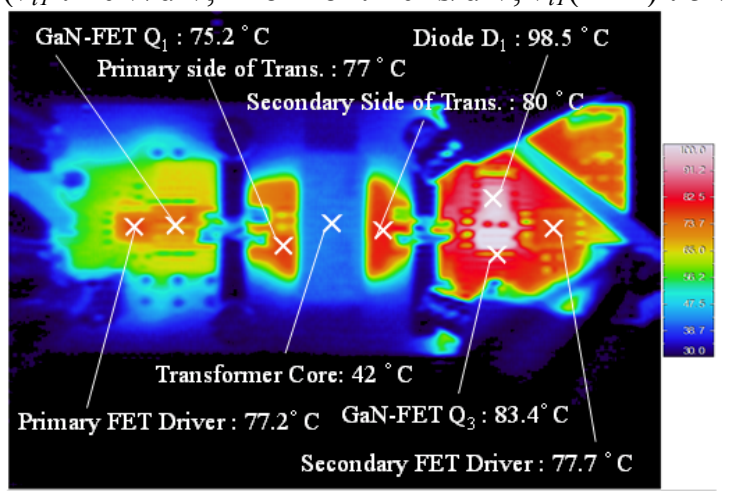

(a) Non-applying phase-shift

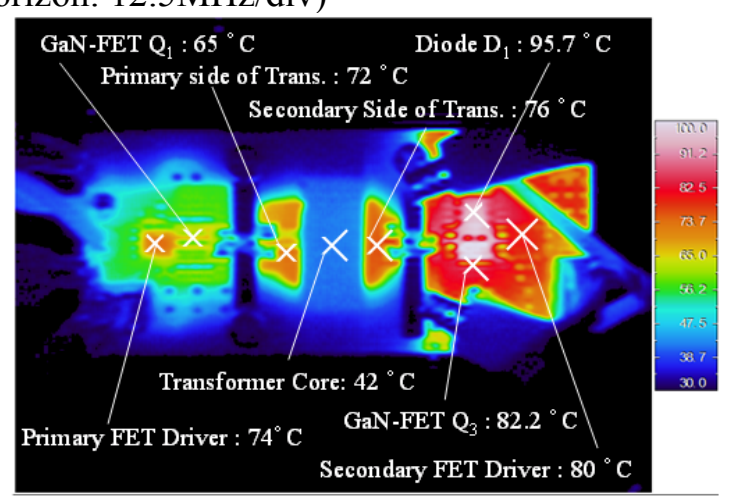

(b) Applying phase-shift

Fig. 14: Thermographic image of the breadboard at point A in Fig. 15

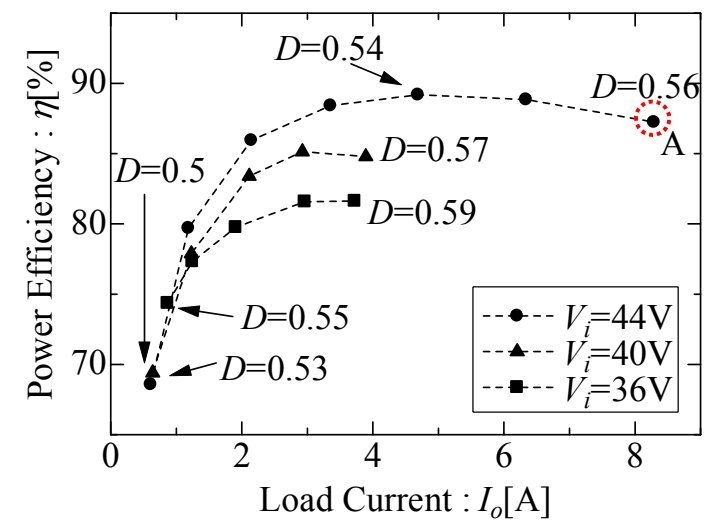

(a) Non-applying phase-shift

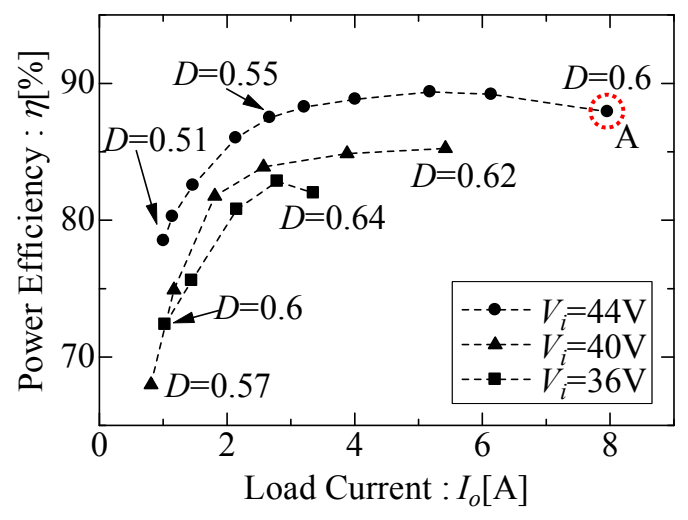

(b) Applying phase-shift

Fig. 15: Power efficiency of the converter 


\section{Conclusion}

In this paper, a new operation for the current-mode resonant converter has been proposed. It was experimentally confirmed that the output voltage is controlled by changing the duty ratio of secondary-side switches with the fixed switching frequency.

Some experiments have been done with the resonant converter regulated by $\mathrm{PWM}$ at $5 \mathrm{MHz}$ of switching frequency. From the results, ZVS operation condition was confirmed at $10 \%$ input variation and $20 \%$ load current variation. Maximum power efficiency is $89.4 \%$. The total power efficiency improvement cannot be found the effect of the phase-shift because of the large power loss of the secondary side. However, the power loss of the primary side is improved.

As the future work, measurement of the current waveform and analysis of the loss distribution, analysis of boost-mode operation, comparison with PFM control, realization of the wide control range and higher power efficiency and feedback control by digital controller are under considerations.

\section{References}

[1] K. Matsuura, H. Yanagi, S. Tomioka, T. Ninomiya, "Power-Density Development of a 5MHz-Switching DCDC Converter," IEEE APEC 2012, pp.2326-2332

[2] Y. Xi, M. Chen, K. Nielson, and R. Bell, "Optimization of the Drive Circuit for Enhancement Mode Power GaN FETs in DC-DC Converters," IEEE PESC2008, pp.2975-2981

[3] W. Choi, S. Young, D. Son, S. Shin and D. Hyun, "Consideration to minimize power losses in Synchronous Rectification," IEEE ICPE2011, pp.2899-2905

[4] D. Costinett, H. Nguyen, R. Zane, and D. Maksimovic, "GaN-FET Based Dual Active Bridge DC-DC Converter," IEEE APEC2011, pp.1425-1432

[5] S. Ji, D. Reusch and F. C. Lee, "High-Frequency High Power Density 3-D Integrated Gallium-Nitride-Based Point of Load Module Design,” IEEE Trans. Power Electron. Vol. 28, No. 9, 2013, pp.4216-4226

[6] T. Hashimoto, T. Ninomiya, H. Tanaka, R. P. Tymerski, "ZVS-PWM-Controlled Parallel-Resonant Converter Applied to A Constant-Current Power Supply," IEEE PESC1999, pp.275-280

[7] T. Zaitsu, T. Ninomiya, M. Shoyama, and H. Tanaka, "PWM-Controlled Current-Mode Resonant Converter Using an Active-Clamp Technique," IEEE PESC1996, pp.89-93

[8] J. R. Pinheiro, I. Barbi, "Three-Level Zero-Voltage-Switching PWM DC-DC Converters A Comparison," IEEE PESC1995, pp.914-919

[9] F. S. Tsai, F. C. Lee, "A Complete DC Characterization of A Constant-Frequency, Clamped-Mode, SeriesResonant Converter," IEEE PESC1988, pp.987-996

[10] W. J. Lee, S. W. Choi, C. E. Kim, and G. W. Moon, “A New PWM-Controlled Quasi-Resonant Converter for a High Efficiency PDP Sustaining Power Module," IEEE Trans. Power Electron. Vol. 23, No.4, 2008, pp. $1782-1790$

[11] C. F. Jin, T. Ninomiya, and S. Tomioka, "Dynamic Characteristics of LLC Current-Resonant DC-DC Converter," IEICE EE 2008, pp.1-6 